\title{
One-port nonlinear electric circuit for simulating grounding systems under impulse current
}

\author{
Ruy Alberto Corrêa Altafim ${ }^{\mathrm{a}}$, Luiz Gonçalves Jr. ${ }^{\mathrm{b}}$, Ruy Alberto Pisani Altafim ${ }^{\mathrm{c}, *}$, \\ Renato Crivellari Creppe ${ }^{\mathrm{b}}$, Alexandre Piantini ${ }^{\mathrm{d}}$ \\ a Electrical Engineering Department, Engineering School of São Carlos, University of São Paulo, São Carlos, SP, Brazil \\ ${ }^{\mathrm{b}}$ Electrical Engineering Department, State University of São Paulo Júlio de Mesquita Filho, Bauru, SP, Brazil \\ ${ }^{c}$ Computer Systems Department, Informatics Center, Federal University of Paraíba, João Pessoa, PB, Brazil \\ ${ }^{\mathrm{d}}$ Institute of Energy and Environment, University of São Paulo, São Paulo, SP, Brazil
}

\section{A R T I C L E I N F O}

\section{Article history:}

Received 10 March 2015

Received in revised form 10 September 2015

Accepted 11 September 2015

Available online 30 September 2015

\section{Keywords:}

Grounding

Impulse impedance

Impulse current

Electric circuit simulation

\begin{abstract}
A B S T R A C T
A one-port nonlinear electric circuit to simulate grounding systems behaviors under high impulse currents is presented. The circuit is based on Loboda's and Pochanke's equations, which describe nonlinear behaviors of soil ionization phenomena. One of the major features of this nonlinear circuit is the possibility to simulate both ionization regions (linear and nonlinear) as a complete grounding system, in commercial simulation software such as Pspice, WorkBench ${ }^{\circledR}$, ATP or EMTP. In order to determine the linear and nonlinear circuit parameters, two known impulse current curves $i(t)$ were applied on scale models and the corresponding impulse voltages $U(t)$ were measured. From these circuit parameters, the $U(t) \times i(t)$ experimental curves were compared with one-port simulated results and the similarities, evaluated using the Area Under Curve (AUC) method, varied in the range 92-99\%. In order to compare simulations with experimental data, a field circuit was elaborated to test three experimental scale models using single rods of different lengths.
\end{abstract}

(c) 2015 Elsevier B.V. All rights reserved.

\section{Introduction}

The protection of electrical power equipment is strongly related to grounding systems, therefore understanding their behavior under different electrical stimulations is fundamental for the proper design and evaluation of these systems.

The resistance of grounding systems submitted to industrial power frequency currents are linear, well-known and can be predicted by equations and mathematical models obtained from measurements of the soil resistivity. However, when these systems are subjected to impulse currents they can also present transient nonlinear behaviors, which are more complex.

The study of the transient behavior of grounding systems dates back to 1929, when Towne described it for the first time subjecting a grounding system to lightning strikes [1]. Since then researchers have proposed different methods to simulate the nonlinear behavior of grounding systems subject to impulse currents. In 1934, a systematic experimental and theoretical investigation into this transient phenomenon was conducted by Bewley as part of his

\footnotetext{
* Corresponding author. Tel.: +55 83999272909.

E-mail address: altafim@gmail.com (R.A. Pisani Altafim).
}

research on lightning protection in power systems [2]. After Bewley's experiments, many other models were proposed to simulate nonlinear grounding phenomena, mainly based on the assumption that the nonlinear behavior of the impedance of an electrode is due to an ionization zone that appears surrounding the electrode when the soil critical breakdown electric field strength is exceeded [3-6].

In 1981, Kosztaluk and others developed a model to simulate ionization-grounding zones by studying the transient behavior of ground impedances with surge arrester varistor blocks [7]. Later in 1984, Velazquez and Mukhedkar investigated the same behavior under high impulse currents by means of an equivalent circuit model for long ground electrode, considering the non-linear and linear behavior of soil. This equivalent circuit based on the concept of telegraphy line was solved with a specific computational algorithm [8].

Later in 1985, Loboda and Pochanke $[9,10]$ investigated the transient analysis of grounding systems by determining surge characteristics of grounding under non-uniform electric fields. From this, a set of equations to evaluate the transient impulse impedance, the voltage and the current distributions in any part of a single or complex grounding electrode was developed. Afterwards, they performed a numerical approximation on the experimental data and calculated some electrical parameters [11], which were in 1992, 


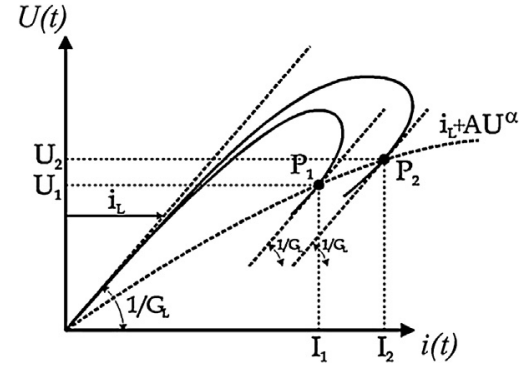

Fig. 1. Illustration of the voltage nonlinear behavior of a grounding system for two different impulse currents obtained from experimental results.

used to simulate the Electromagnetic Transient Problem (EMTP) for different soil conditions in a simulation software such as Alternative Transient Program (ATP) [12]. Other methodologies employed on determination of soil ionization can be found in the review presented in [13].

In 1990, Altafim et al. developed a one-port electric circuit for investigating earthing electrodes associations under impulse currents [14]. This circuit implemented only considering simulations of the nonlinear behavior of grounding systems could be implemented in electric circuit simulation software such as, Pspice and WorkBench ${ }^{\circledR}$, which are easy and reliable tool for solving complex electric circuits.

In the present work the circuit developed by Altafim et al. was extended to simulate both linear and nonlinear behaviors as in a complete grounding system. A detailed mathematical description of the circuit demonstrating its similarity with Loboda and Pochanke equations is presented followed by experimental tests in scale models and simulations with the one-port nonlinear circuit.

\section{One-port nonlinear equivalent circuit model}

The present one-port nonlinear circuit was developed based on experimental data obtained from field tests elaborated with single rod scale models. From these tests, the corresponding $U(t) \times i(t)$ curves, where $U(t)$ is the measured impulse voltage and $i(t)$ is the applied impulse current, were obtained. These curves, presented in Fig. 1 are well described by the Loboda and Pochanke equations (1) and (2) [9], and provide the necessary parameters to represent the nonlinear behavior of a grounding system subjected to an impulse current.

$i(t)=G_{L} \cdot U(t)+i_{N}(t)$

$\frac{d i_{N}(t)}{d t}=\frac{1}{T}\left[A \cdot U(t)^{\alpha}-i_{N}(t)\right]$

In Eqs. (1) and (2), $i(t)$ is the total current over time, $G_{L}$, the conductance, $i_{N}(t)$, the current in the nonlinear region and the parameters $A, T$, and $\alpha$ depend on the analyzed grounding system and soil conditions.

These equations can be expressed by two dependent current sources, one dependent of $U(t)$ and the other of $i_{N}(t)$, one inductor, and three resistances, as illustrated in Fig. 2, which shows the proposed one-port equivalent circuit model.

In order to demonstrate the one-port circuit equivalence to (1) and (2), Kirchhoff's laws were applied leading to (3)-(7) as follows:

$$
\begin{aligned}
& i(t)=i_{L}(t)+i_{N}(t) \\
& i_{L}(t)=G_{L} \cdot U(t)
\end{aligned}
$$

$$
\text { or }
$$

$L_{N} \frac{d i_{N}(t)}{d t}=R_{N 0} \cdot i_{0}(t)-R_{N} \cdot i_{N}(t)$

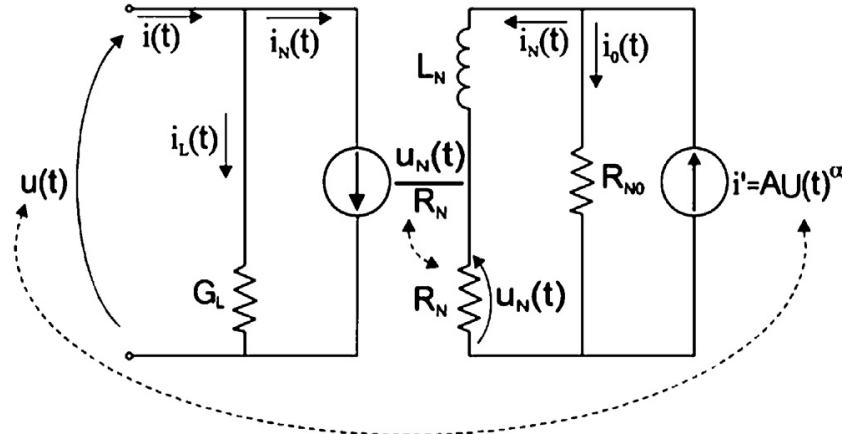

Fig. 2. Schematic representation of the one-port equivalent electric circuit model developed to simulate Loboda and Pochanke equations.

$i_{0}(t)=A \cdot U(t)^{\alpha}-i_{N}(t)$

where $i_{L}(t)$ is the current in the linear region and $R_{N 0}$ and $R_{N}$ are resistances, and $L_{N}$ is an inductance.

From a direct comparison between (5) and (6) and (1) and (2), only a close similarity is observed. However, if $R_{N 0}$ is much larger than $R_{N}$ and $i_{0}(t)$ from (6) is replaced in (5), then:

$\frac{d i_{N}(t)}{d t}=\frac{R_{N 0}}{L_{N}}\left[A \cdot U(t)^{\alpha}-i_{N}(t)\right]$

And if one considers $1 / T$ equal to $R_{N 0} / L_{N}$ and replace (4) into (3), the Eqs. (3) and (7) become identical to Lododa and Pochanke equations Eqs. (1) and (2), respectively.

\subsection{Circuit parameters}

The one-port equivalent circuit parameters and constants were obtained as described:

\subsubsection{Conductance $\mathrm{G}_{\mathrm{L}}$}

The conductance $G_{L}$, which corresponds to the linear region of the grounding system represented in (8), was determined by replacing (4) in (3) and differentiating (3) in relation to the current $i(t)$ at $t=0$.

$G_{L}=\frac{1}{\left.\frac{d U(t)}{d i}\right|_{t=0}}$

To obtain the conductance $G_{L}$ from the experimental curves $U(t) \times i(t)$, the mean value of derivatives for three points closed to $t=0$ was determined for each of the two curves, avoiding unstable value.

\subsubsection{Constants $\alpha$ and $\mathrm{A}$}

The nonlinear voltage behavior of a grounding system is presented in Fig. 1 for two different impulse currents. At the points $P_{1}$ and $P_{2}$ the derivative of $U(t)$ with respect to $i(t)$ is equal to $1 / G_{L}$ i.e. $(d U(t) / d i(t))=1 / G_{L}$, and the currents $i(t)$ at these points are equal to $A U(t)^{\alpha}+G_{L} U(t)$. Thus, from $P_{1}$ and $P_{2}$ coordinates, i.e. $\left(I_{1}, U_{1}\right)$ and $\left(I_{2}, U_{2}\right)$, expressed in (9), the constants $\alpha$ and $A$ can be determined from (10) and (11), respectively.

$$
\begin{aligned}
& \left(\frac{U_{1}}{U_{2}}\right)^{\alpha}=\frac{I_{1}-G_{L} \cdot U_{1}}{I_{2}-G_{L} \cdot U_{2}} \\
& \alpha=\frac{\left.\ln \left(I_{1}-G_{L} \cdot U_{1}\right) /\left(I_{2}-G_{L} \cdot U_{2}\right)\right)}{\ln \left(\left(U_{1}\right) /\left(U_{2}\right)\right)} \\
& A=\frac{I_{1}-G_{L} \cdot U_{1}}{U_{1}^{\alpha}}
\end{aligned}
$$




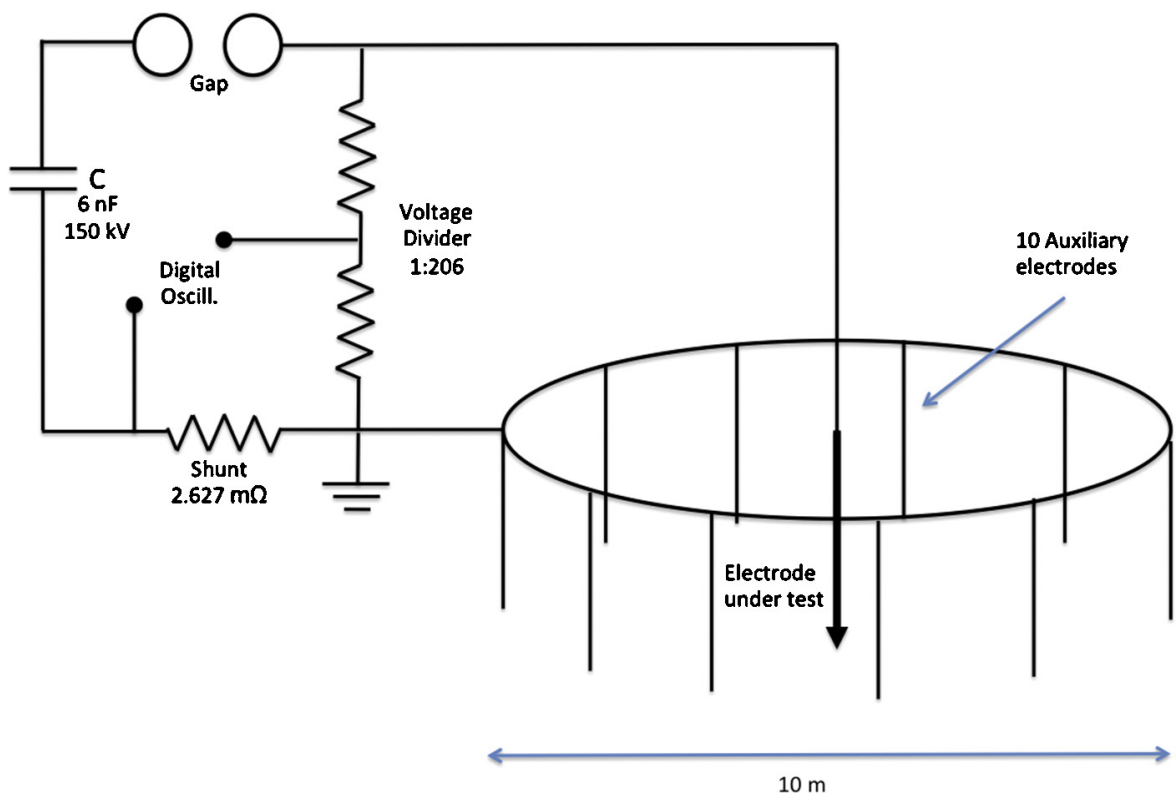

Fig. 3. Experimental test circuit and scale model used to study the linear and nonlinear behavior of grounding rods subjected to impulse currents.

\subsubsection{Parameters $\mathrm{R}_{\mathrm{NO}}, \mathrm{R}_{\mathrm{N}}$ and $\mathrm{L}_{\mathrm{N}}$}

The parameters $R_{N 0}, R_{N}$ and $L_{N}$ can be determined replacing (4) in (3) and deriving the function with respect to $t$, thus obtaining (12):

$\frac{d i(t)}{d t}=G_{L} \frac{d U(t)}{d t}+\frac{d i_{N}(t)}{d t}$

If one considers the maximum value $U(t)$ at a critical time $t_{c r}$, the derivative of $U(t)$ with respect to $t$ is equal to zero, and (12) becomes:

$\left.\frac{d i(t)}{d t}\right|_{t_{c r}}=\left.\frac{d i_{N}(t)}{d t}\right|_{t_{c r}}$

Replacing time $t$ by the critical time $\left(t_{r c}\right)$ in (7), one obtains (14), and if (13) is replaced in (14), the relation between $R_{N 0}$ and $L_{N}$ can be expressed as indicated in (15).

$\left.\frac{d i_{N}(t)}{d t}\right|_{t=t_{c r}}=\frac{1}{T}\left[A \cdot U\left(t_{c r}\right)^{\alpha}-i_{N}\left(t_{c r}\right)\right]$

$\frac{1}{T}=\frac{R_{N 0}}{L_{N}}=\frac{\left.\frac{d i(t)}{d t}\right|_{t=t_{c r}}}{A \cdot U\left(t_{c r}\right)^{\alpha}-i\left(t_{c r}\right)+G_{L} \cdot U\left(t_{c r}\right)}$

As the parameter $1 / T=R_{N 0} / L_{N}$ calculated in Eq. (15) is constant for each particular test rod, and assuming an arbitrary value to $L_{N}$, it is possible to calculate $R_{N 0}$ and then determine $R_{N}$. In order to demonstrate this, in this work the $L_{N}$ was simulated with values ranging from $1 \mathrm{mH}$ to $100 \mathrm{mH}$ and $R_{N}$ was consider at least 1000 times smaller than $R_{N O}$.

\section{Experimental}

\subsection{Experimental setup}

In order to reproduce the nonlinear behavior, such as those shown in Fig. 1, three scale model grounding systems, as shown in Fig. 3 were set. To compose this scale model, ten auxiliary metal rods with a diameter of $25 \mathrm{~mm}$ and $2.5 \mathrm{~m}$ long were buried into the soil with an electrical resistivity of $100 \Omega \mathrm{m}$, forming a circumference of $10 \mathrm{~m}$ in diameter. The rods were equally spaced and connected with a copper strip. At the center of the circumference, a test scale model was installed and connected to an impulse generator composed of one capacitor (C) of $6 \mathrm{nF}$ and $150 \mathrm{kV}$ and one controlled air-gap. A shunt resistor of $2.627 \mathrm{~m} \Omega$ and a voltage divider with a 1:206 ratio connected to a digital oscilloscope completed the measurement system as indicated in Fig. 3. Three steel wires, $1.5 \mathrm{~mm}$ in diameter and $0.4,0.6$ and $0.90 \mathrm{~m}$ in length, were employed as scale models. The stray inductance of the experimental circuits is difficult to determine and measure, but its value was maintained lower enough to avoid oscillations in the impulse current waveform.

To attain the soil ionization condition around the scale model electrodes, the experiments were conducted with surface current densities between 2 and $8 \mathrm{~A} / \mathrm{cm}^{2}$ as suggested in [7].

\subsection{Experimental data}

Experimental tests were performed applying an impulsive current to the scale models and measuring the impulsive voltage as represented in the oscillogram in Fig. 4a. From the oscillograms, the one-port electric circuit parameters were obtained by measuring the voltage amplitude peak $\left(U_{\max }\right)$, the current amplitude peak $\left(I_{\max }\right)$, and their correspondent front rise time $\left(T_{1}\right)$ and the time when the impulse wave reached half of the peak $\left(T_{50 \%}\right)$. These values, considering two sets of curves $U(t) \times i(t)$ for each of the three scale models, are presented in Table 1.

Based on these measured values, the parameters $I_{0}, U_{0}, \alpha_{1}, \alpha_{2}$, $\beta_{1}, \beta_{2}$ were obtained implementing recursive computational procedures and later used on the oscillogram curves fitting with double exponential waveforms given by (16) and (17), as shown in Fig. 4b and $\mathrm{c}$.

$i(t)=I_{0}\left(e^{-\alpha_{1} t}-e^{-\alpha_{2} t}\right)$

$U(t)=U_{0}\left(e^{-\beta_{1} t}-e^{-\beta_{2} t}\right)$

In Eqs. (16) and (17), $I_{0}, \alpha_{1}, \alpha_{2}, U_{0}, \beta_{1}, \beta_{2}$ are constant values presented in Tables 2 and 3.

\section{Simulation circuits}

From the experimental data presented in Tables 2 and 3 it was possible to determine the one-port equivalent circuit parameters shown in Fig. 2 and simulate the linear and nonlinear behaviors 
a)

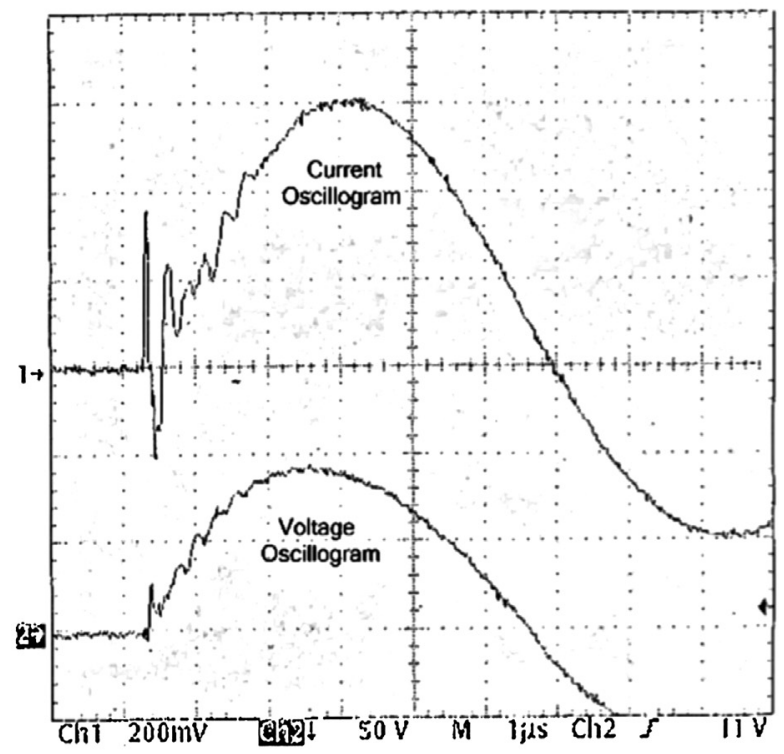

b)

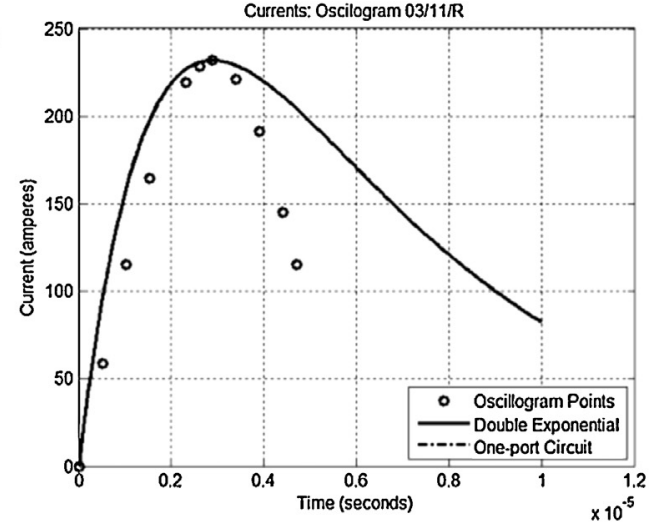

c)

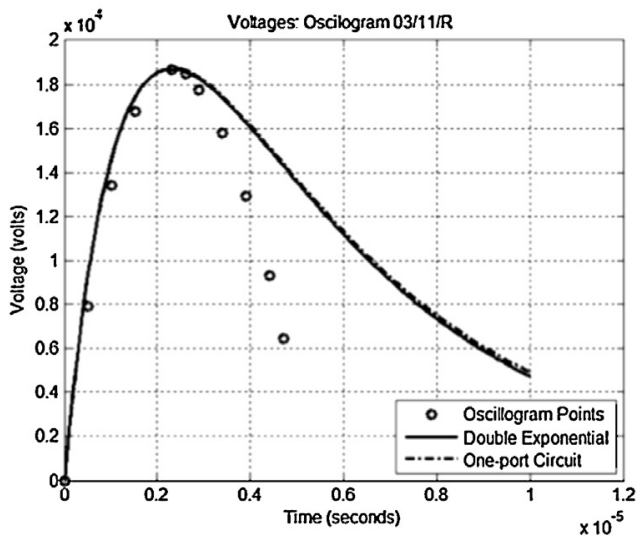

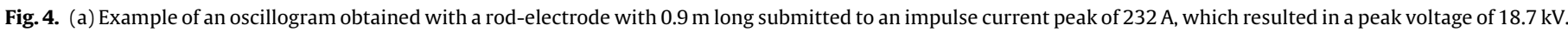

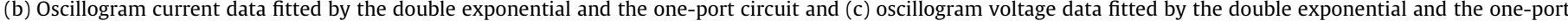
circuit.

Table 1

Extracted data from impulsive curves obtained on the experimental results.

\begin{tabular}{|c|c|c|c|c|c|c|c|}
\hline \multirow[t]{2}{*}{ Scale model length (m) } & \multirow[t]{2}{*}{ Oscgrm. } & \multicolumn{3}{|l|}{ Voltage } & \multicolumn{3}{|l|}{ Current } \\
\hline & & $U_{\max }(\mathrm{kV})$ & $T_{1}(\mu \mathrm{s})$ & $T_{50 \%}(\mu \mathrm{s})$ & $I_{\max }(\mathrm{A})$ & $T_{1}(\mu \mathrm{s})$ & $T_{50 \%}(\mu \mathrm{s})$ \\
\hline 0.4 & $11 / 11 / \mathrm{R}$ & 24.0 & 1.8 & 6.03 & 91.0 & 2.6 & 7.59 \\
\hline 0.4 & $12 / 11 / \mathrm{R}$ & 28.8 & 1.9 & 6.31 & 124.0 & 2.8 & 8.02 \\
\hline 0.6 & $07 / 11 / \mathrm{R}$ & 21.1 & 1.9 & 5.86 & 138.0 & 2.4 & 6.80 \\
\hline 0.6 & $08 / 11 / \mathrm{R}$ & 24.0 & 2.0 & 6.05 & 184.0 & 2.6 & 7.45 \\
\hline 0.9 & $03 / 11 / R$ & 18.7 & 2.3 & 6.88 & 232.0 & 2.9 & 8.23 \\
\hline 0.9 & $04 / 11 / \mathrm{R}$ & 22.3 & 2.2 & 6.48 & 283.0 & 2.7 & 7.69 \\
\hline
\end{tabular}

Table 2

Parameters of impulse current for the double exponential.

\begin{tabular}{llll}
\hline Oscillogram & $I_{0}(\mathrm{~A})$ & $\alpha_{1}(\mu \mathrm{s})$ & $\alpha_{2}(\mu \mathrm{s})$ \\
\hline $11 / 11 / \mathrm{R}$ & 238 & 0.6336 & 0.2119 \\
$12 / 11 / \mathrm{R}$ & 346 & 0.5737 & 0.2074 \\
$07 / 11 / \mathrm{R}$ & 375 & 0.6865 & 0.2415 \\
$08 / 11 / \mathrm{R}$ & 535 & 0.6016 & 0.2277 \\
$03 / 11 / \mathrm{R}$ & 725 & 0.5228 & 0.2128 \\
$04 / 11 / \mathrm{R}$ & 780 & 0.6022 & 0.2151 \\
\hline
\end{tabular}

of rod-electrodes using WorkBench ${ }^{\circledR}$ simulation software (from Image Technologies Ltd.) with the circuit represented in two correlated parts (I and II) connected to an impulse current generator as shown in Fig. 5.

From Fig. 5 one can observe that part I is composed by the resistor $R_{L}$, equal to $1 / G_{L}$ as shown in Eq. (4), in parallel with the current source (FC1) dependent on current $I_{N}$, which circulate on the resistor $R_{N}$, located on part II. As the gain of FC1 approximates to one, it generates the same current $i_{N}(t)$ on part I. The part II, is also related with the part I by the current source (FC2) dependent on the
Table 3

Parameters of impulse voltage for the double exponential.

\begin{tabular}{llll}
\hline Oscillogram & $U_{0}(\mathrm{kV})$ & $\beta_{1}(\mu \mathrm{s})$ & $\beta_{2}(\mu \mathrm{s})$ \\
\hline $11 / 11 / \mathrm{R}$ & 41291 & 1.2182 & 0.2049 \\
$12 / 11 / \mathrm{R}$ & 53557 & 1.0461 & 0.2075 \\
$07 / 11 / \mathrm{R}$ & 47025 & 0.9281 & 0.2518 \\
$08 / 11 / \mathrm{R}$ & 52502 & 0.9141 & 0.2415 \\
$03 / 11 / \mathrm{R}$ & 45680 & 0.7329 & 0.2262 \\
$04 / 11 / \mathrm{R}$ & 51200 & 0.8183 & 0.2320 \\
\hline
\end{tabular}

voltage $U(t)$ on the resistor $R_{L}$ from part I, and from the function $A U(t)^{\alpha}$, simulating the current $i$ ' in Fig. 2. The two branches in parallel with FC2 complete part II, one containing the resistors $R_{N}$ in series with inductor $L_{N}$ and other with the resistor $R_{N 0}$. The obtained simulate values for the resistances, inductor, and parameters $A$ and $\alpha$ are presented in Table 4 for each respective scale model.

It is worth mentioning that the parameters $A$ and $\alpha$ are very much dependent on small variations of the current and voltage values, which were obtained automatically with a specific software, from the points P1 and P2 coordinates, as shown in Fig. 1. Such 


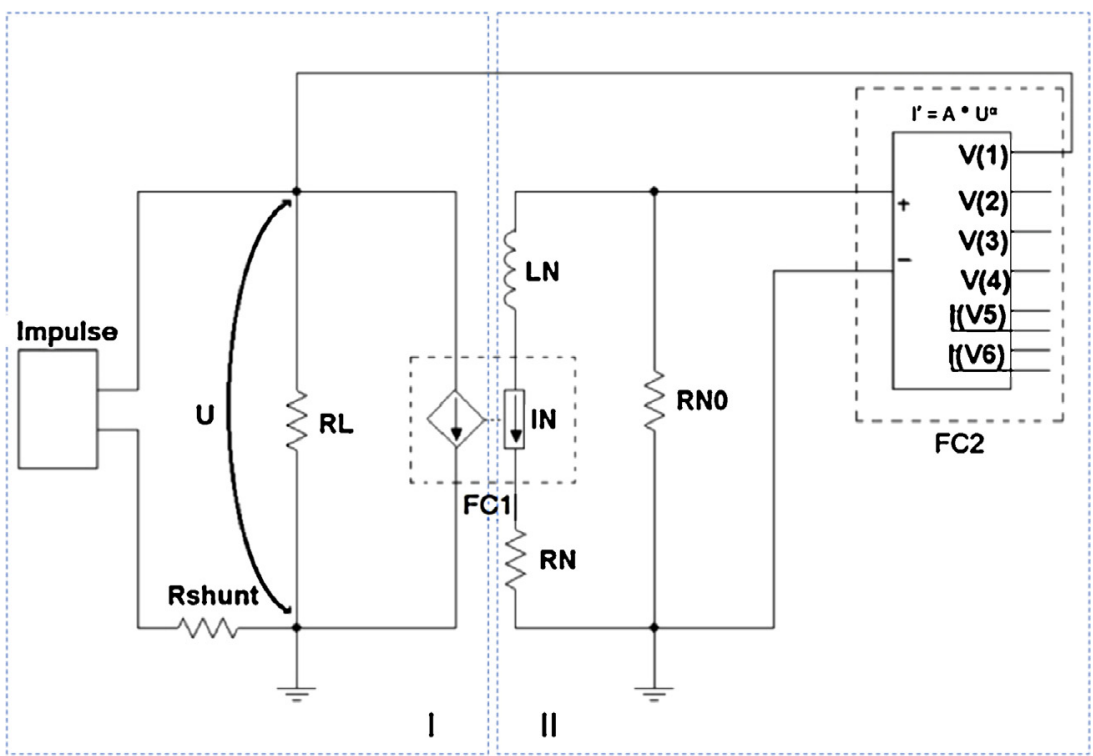

Fig. 5. One-port circuit model composed by the interconnected parts I and II simulated in WorkBench for a rod-electrode grounding configuration.

Table 4

Parameters of the one-port circuit model.

\begin{tabular}{|c|c|c|c|c|c|c|}
\hline \multirow[t]{2}{*}{ Scale model length (m) } & \multicolumn{4}{|c|}{ Circuit parameters } & \multicolumn{2}{|c|}{ Nonlinear source parameters } \\
\hline & $R_{L}(\Omega)$ & $R_{N}(\mathrm{~m} \Omega)$ & $R_{N 0}(\Omega)$ & $L_{N}(\mu \mathrm{H})$ & $\alpha$ & $A$ \\
\hline 0.4 & 385 & 39.2 & 39.2 & 100 & 2.06 & $6.08 \mathrm{E}-08$ \\
\hline 0.6 & 183 & 12.8 & 12.8 & 100 & 4.85 & $9.90 \mathrm{E}-20$ \\
\hline 0.9 & 101 & 43.7 & 43.7 & 100 & 1.06 & $2.44 \mathrm{E}-03$ \\
\hline
\end{tabular}

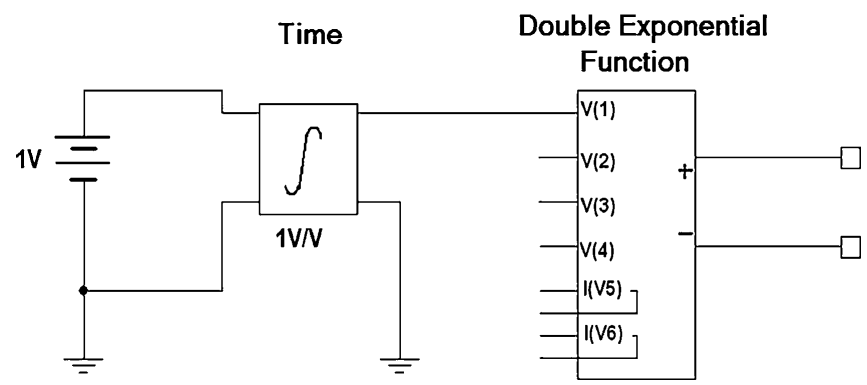

Fig. 6. Impulse current generator modulated from a voltage dependent current source, having a variable time $(t)$, emulated as a voltage source $V_{(1)}$.

variations can lead to very large differences in the parameters $A$ and $\alpha$ as can be seen in the results presented on Table 4 for the $0.6 \mathrm{~m}$ scale model.

The impulse current generator with double exponential waveforms described in (16) was simulated as a dependent current source called double exponential function of voltage, as shown in Fig. 6 and described by (18), where $v_{(1)}$ corresponds to the simulation time variable, obtained by integrating a DC voltage source equal to $1 \mathrm{~V}$.

$i(t)=I_{0}\left(e^{-\alpha_{1} v_{(1)}}-e^{-\alpha_{2} v_{(1)}}\right)$

\section{Results}

The $U(t) \times i(t)$ curves from the experimental results and from those simulated with the one-port circuit for the parameters indicated in Table 4 are shown in Figs. 7-9, for the 0.4, 0.6 and $0.9 \mathrm{~m}$ scale models, respectively. From these, one can observe that the

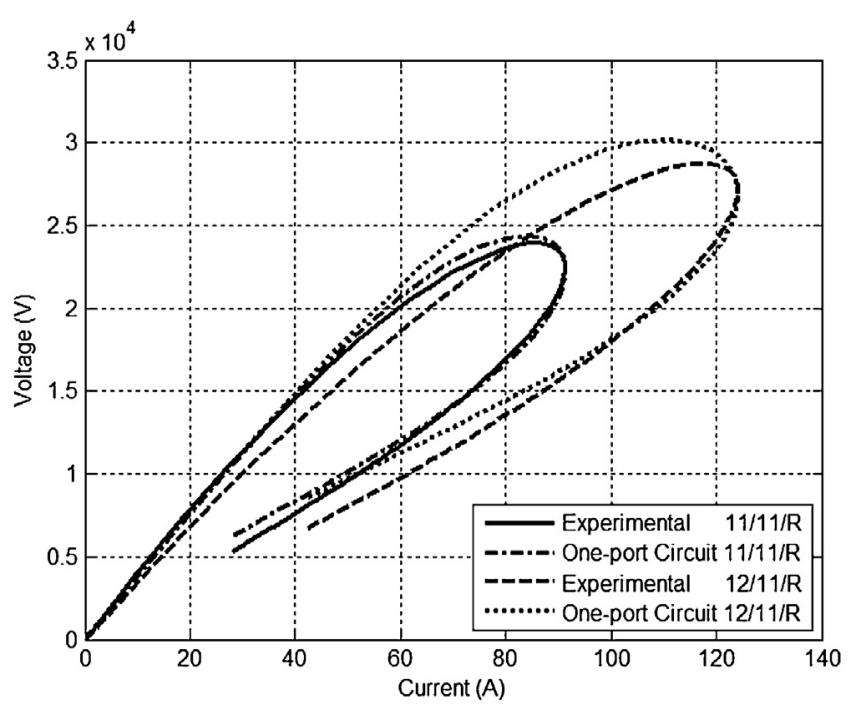

Fig. 7. Simulated and experimental voltage and current curves for $0.4 \mathrm{~m}$ rod scale models.

one-port equivalent circuit, proposed here, simulates both linear and nonlinear ionization behavior with certain agreement.

The similarity between the experimental and simulated results was verified through the Area Under Curve (AUC) method, which was performed on the impedance curves over time i.e. dividing the voltages values by it correspondent current and plotting over the time, for each model. Then by comparing the areas under these curves, from simulated and experimental data, an approximation of more than $90 \%$ between curves was obtained, as can be seen in Table 5 . 


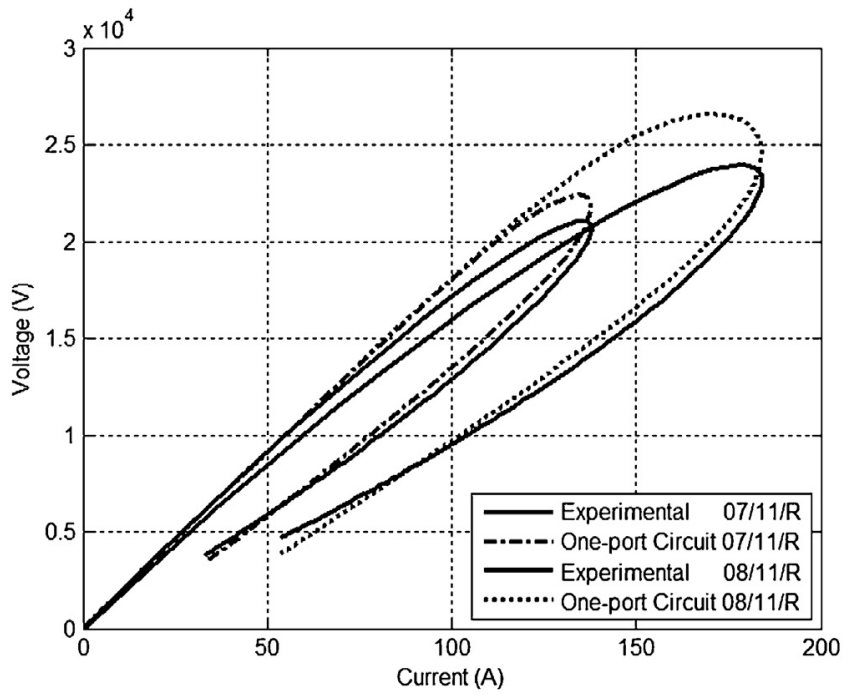

Fig. 8. Simulated and experimental voltage and current curves for $0.6 \mathrm{~m}$ rod scale models.

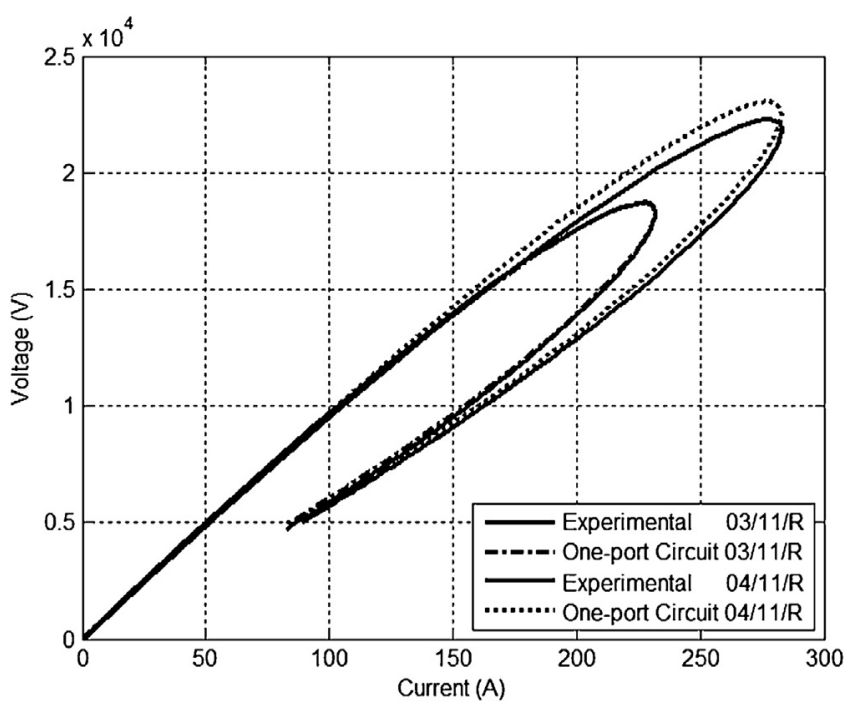

Fig. 9. Simulated and experimental voltage and current curves for $0.9 \mathrm{~m}$ rod scale models.

Table 5

Similarity between the areas under curves (AUC) from simulated and experimental impedance curves.

\begin{tabular}{ll}
\hline Oscillogram & AUC similarity $(\%)$ \\
\hline $11 / 11 / R$ & 97.01 \\
$12 / 11 / R$ & 92.27 \\
$07 / 11 / R$ & 97.58 \\
$08 / 11 / R$ & 95.58 \\
$03 / 11 / R$ & 99.08 \\
$04 / 11 / R$ & 97.36 \\
\hline
\end{tabular}

A possible explanation for the small divergence between the experimental and simulated results is the use of a double exponential equation to fit the oscillogram curves, from which the parameters used in the open-circuit were calculated, and as presented in Fig. 4b and $\mathrm{c}$ is not ideal for this fitting.

Nevertheless, adjustments in the one-port circuit can be performed by small punctual changes in related parameters, such as, $T, A$ and $\alpha$. And to demonstrate how this relation affects the

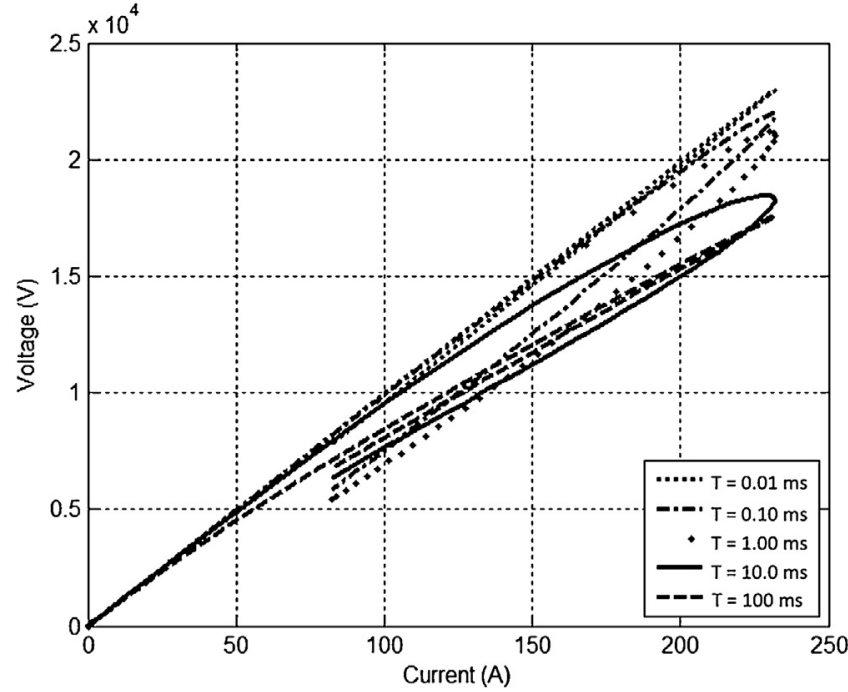

Fig. 10. Behavior of simulated one-port circuit from oscillograms $3 / 11 / R$ regarding parameter $T$ in the circuit, with $A$ and $\alpha$ fixed.

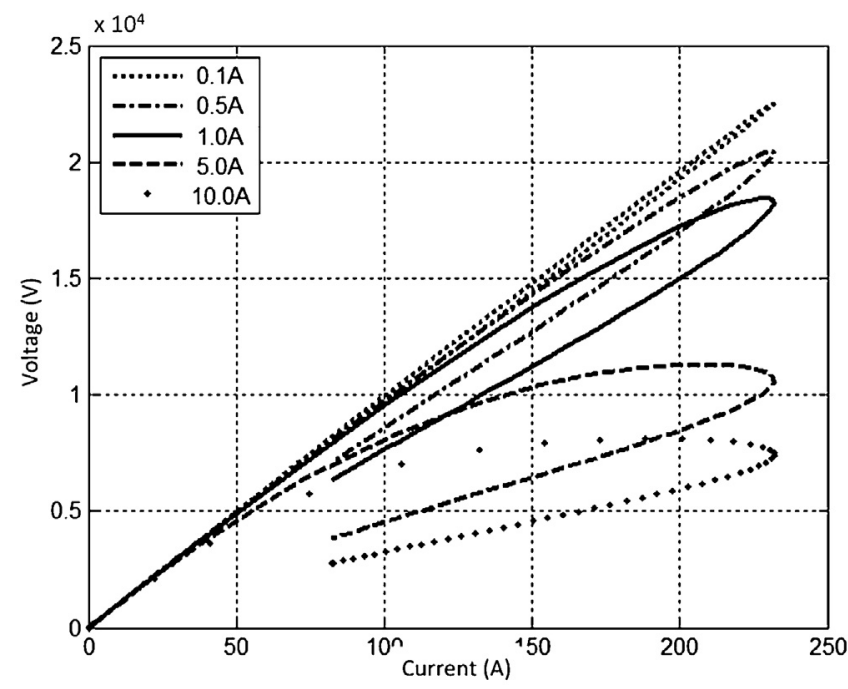

Fig. 11. Behavior of simulated one-port circuit from oscillograms $3 / 11 /$ R regarding parameter $A$ of the dependent current $A U(t)^{\alpha}$, with parameters $\alpha$ and $T$ fixed.

one-port circuit simulation, a series of simulations were performed on a $0.9 \mathrm{~m}$ scale model considering random and fixed values. For instance, in Fig. 10, the parameter $T$ was varied from 0.01 up to $100 \mathrm{~ms}$, while the parameters $A$ and $\alpha$ remained constant at $5.72 \times 10^{-5}$ and 1.41 , respectively. In Fig. 11, the parameter $A$ was varied from 0.1 to 10 while the other two parameters were fixed, with $T=1.16 \mathrm{~ms}$ and in Fig. 12, $\alpha$ was adjusted in the range of $0.9-1.1$ in steps of 0.05 and the parameters $A$ and $T$ remained fixed with previous values.

In Fig. 10 one can observe that variating the parameter $T$ from 0.01 to $100 \mathrm{~ms}$ the loop area increase as $T$ approximates to a maximum value and starts to decay with further increment e.g. $T=100 \mathrm{~ms}$. Changes in the parameter $A$ and $\alpha$ showed in Figs. 11 and 12 present a similar effect i.e. with the increase in the parameter $A$ and $\alpha$ the loop also becomes broader, but a major effect involves a reduction on the voltage amplitude with the increasing parameter. This simulation shows how the curves can be adjusted to better fit the experimental results with the one-port equivalent circuit. 


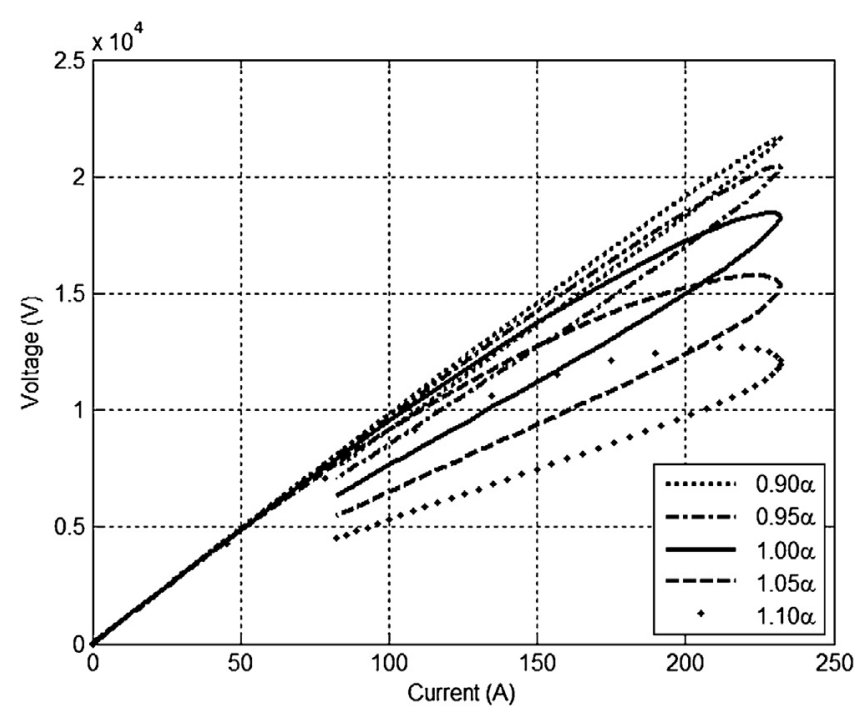

Fig. 12. Behavior of simulated one-port circuit from oscillograms $3 / 11 / \mathrm{R}$ regarding parameter $\alpha$ of the dependent current $A U(t)^{\alpha}$, with $A$ and $T$ fixed.

\section{Conclusion}

A one-port equivalent circuit model was presented as an alternative to Loboda and Pochanke equations to simulate the linear and nonlinear behavior of grounding systems under impulse currents using circuit simulation software. The one-port circuit parameters were obtained from realistic experimental data derived from tests on scale model grounding systems consisting of rod-electrodes of different lengths $(0.4,0.6$ and $0.90 \mathrm{~m})$. The experimental and simulated results were compared and an agreement of more than $90 \%$ was obtained. This indicates that the one-port circuit is a reliable simulation tool, which can be further improved by adjusting some parameters. Another contribution of this work was the implementation of an impulse current generator to simulate the impulse currents, with the variable time simulation emulated by integrating a DC voltage source. The errors presented by the model were mainly caused by the circuit parameters determination. Further studies are already being carried out in order to improve the process of parameters determination and to verify the usefulness of the application of the one-port circuit to investigate the behavior of larger grounding systems. Besides, preliminary studies have also been initiated to verify the possibility of extrapolating the use of the developed circuit to simulate the behaviors of other nonlinear system components such as transmission and distribution surge arresters.

\section{Acknowledgements}

The authors would like to thank IEE/USP for the implementation of the experimental setup and RGE-CPFL and ELEKTRO - ANEEL for the financial support. The authors are very grateful to Eng. Omar Sacilotto for his pertinent observations during the development process.

\section{References}

[1] I.F. Gonos, I.A. Stathopulos, Soil ionisation under lightning impulse voltages, IEEE Proceedings Science Measurement and Technology 151 (2004) 343-346.

[2] L.V. Bewley, Theory and tests of the counterpoise, Electr. Eng. (1934) 1163-1172.

[3] W.A. Chisholm, W. Janischewskyj, Lightning surge response of ground electrodes, IEEE Transactions on Power Delivery 4 (1989) 1329-1337.

[4] E.E. Oettle, A new general estimation curve for predicting the impulse impedance of concentrated earth electrodes, IEEE Transactions on Power Delivery 3 (1988) 2020-2029.

[5] Y. Liu, Transient Response of Grounding Systems caused by Lightning: Modelling and Experiments, Uppsala University, Interfaculty Units, Acta Universitatis Upsaliensis, Uppsala, Sweeden, 2004, pp. 89.

[6] A.C. Liew, M. Darveniza, Dynamic model of impulse characteristics of concentrated earths, Proceedings of the Institution of Electrical Engineers-London 121 (1974) 123-135.

[7] R. Kosztaluk, M. Loboda, D. Mukhedkar, Experimental study of transient ground impedances, IEEE Transactions on Power Apparatus and Systems 100 (1981) 4653-4660.

[8] R. Velazquez, D. Mukhedkar, Analytical modeling of grounding electrodes transient behavior, IEEE Transactions on Power Apparatus and Systems 103 (1984) 1314-1322.

[9] M. Loboda, Z. Pochanke, Experimental study of electric properties of soil with impulse current injections, in: 18th International Conference on Lightning Protection, VDE-Verlag, Munich, Germany, 1985, pp. 191-198.

[10] M. Loboda, Z. Pochanke, Current and voltage distributions in earthing systems. A numerical simulation based on the dynamic model of impulse soil conductivity, in: 20th International Conference on Lightning Protection, Interlaken, Switzerland, 24-28 September, 1990, pp. 1-7.

[11] M. Loboda, Z. Pochanke, A numerical identification of dynamic model parameters of surge soil conduction based on experimental data., in: 21 th International Conference on Lightning Protection, Berlin, Germany, 22-25 September, 1992, pp. 139-143.

[12] W. Kalat, M. Loboda, Z. Pochanke, Implementation of the dynamic model of surge soil conduction for transient behaviour of grounding electrodes simulations using ATP version of EMTP., in: 22th International Conference on Lightning Protection, Budapest, Hungry, 19-23 September, 1992, pp. 1-4.

[13] F.E. Asimakopoulou, F. Ioannis, I.F. Gonos, I.A. Stathopulos, Methodologies for determination of soil ionization gradient, J. Electrost. 70 (5) (2012) 457-461.

[14] R.A.C. Altafim, D.M. Leite, F. Kameyama, Earthing electrode associations for impulse currents., in: 20th International Conference on Lightning Protection, Interlaken, Switzerland, 24-28 September, 1990, p. 4. 